\title{
Clinical Aspects of Total Colectomy - Laparoscopic Versus Open Technique for Familial Adenomatous Polyposis and Ulcerative Colitis -
}

\author{
YASUMI ARAKI, HIROHARU ISOMOTO, YOSHIAKI TSUZI, ATSUSHI MATSUMOTO, \\ MASAFUMI YASUNAGA, UHI TOH, KENZI YAMAUCHI AND KAZUO SHIROUZU * \\ Department of Surgery, Kurume University Medical Center, Kurume 839-0863 and \\ * Department of Surgery, Kurume University School of Medicine, Kurume 830-0011, Japan
}

\begin{abstract}
Summary: Clinical aspects of laparoscopy combined total colectomy $(L T C)(n=10)$ and open total colectomy $(\mathrm{OTC})(\mathrm{n}=29)$ with ileorectal anastomosis for familial adenomatous polyposis and ulcerative colitis are compared in a retrospective study. The mean operative time was 282 (range, 169 to 420 ) minutes in the LTC group and 274 (range, 139 to 570 ) minutes in the OTC group. The mean volume of operative blood loss was 321 (range, 52 to 728 ) $\mathrm{ml}$ and 471 (range, 48 to 1040) $\mathrm{ml}$ for the LTC and OTC groups, respectively. Nasogastoric tube could be removed after POD 1.2 vs. $5.8(p<0.05$ ), the mean time to passage of stool was 1.9 (range, 1 to 3 ) vs. 5.2 (range, 3 to 7 ) days $(p<0.01)$, and in the LTC group watery stool was soon made solidification after POD 23.4 vs. 84.1 $(p<0.01)$. Laparoscopy combined total colectomy may prove to have one-stage restorative total colectomy without a temporary ileostomy due to early solidification of watery stool and more benefits than conventional open surgery.
\end{abstract}

Key words ulcerative colitis, familial adenomatous polyposis, laparoscopy, total colectomy

\section{INTRODUCTION}

The application of laparoscopic surgery to other gastrointestinal disease has been attracting more attention due to a possibility of its various benefits [1]. Laparoscopy-assisted colectomy has been reported to result in an earlier recovery of the bowel movement and earlier discharge of patients from the hospital compared with open surgery [2-6]. Ulcerative colitis is commonly operated by total colectomy with a $\mathbf{J}$ shaped reservoir [7-9], and the indications of surgical treatment include aggravation of general conditions, toxic megacolon, refractoriness to medical management, massive blood loss, and malignancy. The patients with preoperative administration of more than $15,000 \mathrm{mg}$ of the steroids are at poor risk. Therefore, ulcerative colitis is recommended to be operated by a less invasive procedure. And one of the surgical options for familial adenomatous poly- posis is prophylactic total colectomy with ileorectal anastomosis [10]. However, laparoscopic total colectomy has not been recognized to have more benefits than open surgery [11-13]. Then, here, we report our operative procedure of laparoscopy combined total colectomy and compare it with open procedure to investigate which has more benefits.

\section{PATIENTS AND METHODS}

\section{Patients}

Thirty-nine cases of total colectomy with ileorectal anastomosis for familial adenomatous polyposis $(n=22)$ and ulcerative colitis $(n=17) \quad(10$ cases by laparoscopy combined total colectomy and 29 cases by conventional open surgery) which we have encountered for the last 15 years were included in this study. 


\section{Operative technique}

The preoperative preparation was the same as that used for conventional open surgery. On the day preceding surgery, patients were placed on a clear liquid diet and underwent colonic cleaning using a polyethylene glycol solution [14]. All resections were performed with the patient intubated endotracheally under general anesthesia. Gastric decompression was performed via a nasogastric tube. A 10 $\mathrm{mm}$ trocar was inserted into the sub-umbilical region of the patients in a modified lithotomy position by the open laparoscopy. Pneumoperitoneum is initiated through the sub-umbilical lesion, and three cannulas are placed. The abdominal cavity was first observed for expansion of colic inflammation and other complications. The ascending colon was ablated from the posterior peritoneum and the right transverse colon from the hepato-colic ligament, duodenum and greater omentum. The left transverse colon was cut off from the splenic-colic ligament and the splenic flexture and the posterior peritoneum of the descending colon are mobilized using laparoscopic to ensure the release of the large bowel. After full mobilization of the intra-abdominal portion of the colon as well as partial mobilization of the rectum, minilaparotomy was conducted along the $7 \mathrm{~cm}$ of the lower abdomen. The abdominal wall was suspended using an Omni Tract Retracter to make the huge space inside the abdominal cavity. The rectum and mesenteric vessels were ablated and divided through thus made small wound under direct vision (Fig. 1). The completion of the reservoir and anastomosis were all performed in the standard fashion [9].

\section{Statistical analysis}

Data were obtained from general medical records, operation reports and a questionnare, and analyzed using Student's t-test.

\section{RESULTS}

The patients who underwent LTC or OTC were comparable with regard to age, sex, and degree of obesty (expressed as the ratio of weight per square length) (Table 1). Operative time was defined as the time from incision to dressing and does not include the time for anesthesia before incision. Intraoperative results are listed in Table 2. The mean operative time was not significantly different between the LTC and OTC groups ( $282 \pm 143$ vs. $274 \pm 192 \mathrm{~min}$ ). The mean estimated operative blood loss was $321 \pm 286 \mathrm{ml}$ for the patients in the LTC group and $471 \pm 198 \mathrm{ml}$ in the OTC group. There was no significant difference between two groups.

The patients were treated similarly in terms of diet advance, ambulation, pain medication, and discharge, regardless of operative approach. The recovery of bowel function was studied for the items of nasogastric tube removal, passage of stool, and giving liquid diet (Table 3). The LTC group was earlier than in the OTC group for nasogastric tube

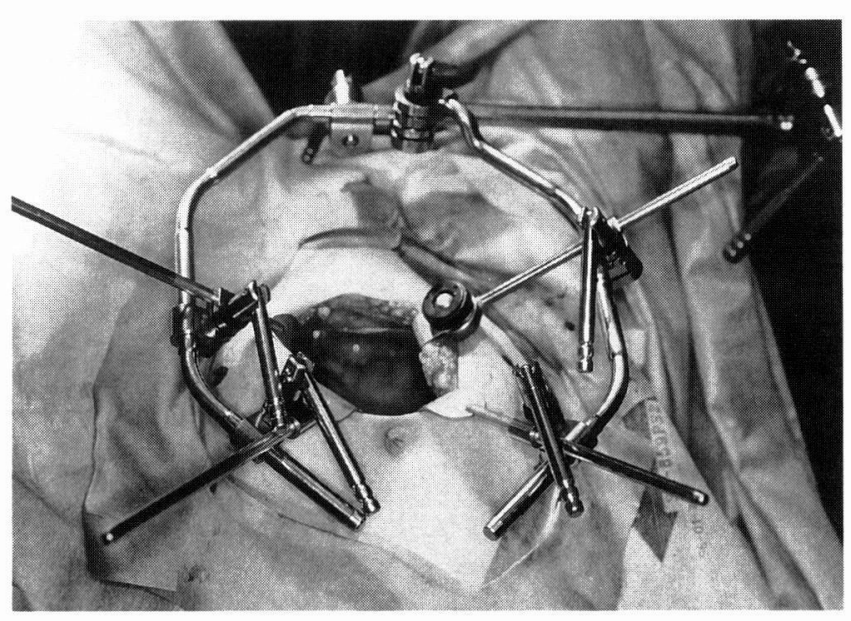

Fig. 1. Operative field with Omni Tract Retracter.

TABLE 1.

Patient characteristics

\begin{tabular}{ccc}
\hline Characteristic & LTC Group $(\mathrm{n}=10)$ & OTC Group $(\mathrm{n}=29)$ \\
\hline $\begin{array}{l}\text { Age of total population (years) } \\
\text { Sex of total population } \\
\text { Male/Female }\end{array}$ & $29.2 \pm 10.2$ & $31.1 \pm 14.3$ \\
Obesty $\left(\mathrm{kg} / \mathrm{m}^{2}\right)$ & $3 / 7$ & $8 / 21$ \\
\hline
\end{tabular}

Results are means $\pm \mathrm{SD}$.

Results for the two groups did not differ significantly ( $p>0.05$, Student's t-test) 
TABLE 2.

Intraoperative operative clinical parameters

\begin{tabular}{cll}
\hline Parameter & LTC Group $(\mathrm{n}=10)$ & OTC Group $(\mathrm{n}=29)$ \\
\hline Operative Time (min) & $282 \pm 143(169-420)$ & $274 \pm 192(139-570)$ \\
Blood loss (ml) & $321 \pm 286(52-728)$ & $471 \pm 198(48-1040)$ \\
\hline
\end{tabular}

Results are means \pm SD.

TABLE 3.

Postoperative clinical parameters

\begin{tabular}{lcc}
\hline Parameter & LTC Group $(\mathrm{n}=10)$ & OTC Group $(\mathrm{n}=29)$ \\
\hline Removal of the nasogastric tube (POD) $^{\mathrm{a}}$ & $1.2 \pm 1.3(1-2)$ & $5.8 \pm 3.8(3-8)$ \\
Passage of stool $^{\mathrm{b}}$ & $1.9 \pm 1.5(1-3)$ & $5.2 \pm 5.9(3-7)$ \\
Liquid Diet (POD) $_{\text {Stool Solidification (POD) }}^{\mathrm{b}}$ & $3.3 \pm 7.6(3-23)$ & $6.8 \pm 12.9(7-28)$ \\
Hospital Stay (POD) & $23.4 \pm 12.3(20-24)$ & $84.1 \pm 29.8(28-121)$ \\
\hline
\end{tabular}

POD: postoperative day; Results are means \pm SD.

aStatistically significant ( $\mathrm{p}<0.05$, Student's t-test).

${ }^{\mathrm{b}}$ Statistically significant $(\mathrm{p}<0.01)$

TABLE 4

Postoperative complications

\begin{tabular}{|c|c|c|}
\hline & LTC Group $(n=10)$ & OTC Group $(n=29)$ \\
\hline \multirow[t]{4}{*}{ Complications } & Anastomotic leak (2) & Anastomotic leak (5) \\
\hline & & MRSA enteritis $^{\mathrm{a}}$ \\
\hline & Wound infection (2) & Wound infection (8) \\
\hline & Ileus & Ileus \\
\hline Morbidity & $30.0 \%$ & $34.5 \%$ \\
\hline Mortality ${ }^{b}$ & $0 \%$ & $3.4 \%$ \\
\hline
\end{tabular}

MRSA: methicillin-resistant Staphylococcus aureus

${ }^{a}$ Major complication

${ }^{\mathrm{b}}$ Cause of death of a patient was MRSA enteritis.

removal (POD $1.2 \pm 1.3$ vs. $5.8 \pm 3.8$; $\mathrm{p}<0.05$ ). The mean time to passage of stool was also significantly shorter in the LTC group (POD $2.1 \pm 1.5$ ) than in the OTC group (POD 5.2 \pm 5.9$)(\mathrm{P}<0.01)$. Giving liquid diet was significantly earlier in the LTC group (POD $3.3 \pm 7.6$ vs. $6.8 \pm 12.9 ; \mathrm{p}<0.05$ ) and in the OTC group watery stool was soon made solidification after POD $23.4 \pm 12.3$ vs. $84.1 \pm 29.8$ ( $\mathrm{p}<0.01)$. Postoperative hospitarization was not significantly different between the LTC group (POD $43.5 \pm 31.2$ ) and the OTC group (POD $46.2 \pm 40.1$ ). In a case of the LTC group, stool was soon made hard and a temporary ileostomy could be closed after one operative month. In another two cases, as the functions of the small bowel were expected to take over those of the large bowel early, total colectomy without temporary ileostomy could be successfully conducted.

The LTC group had fewer complication, and none related to the procedure itself (Table 4). A small wound infection occurred in $20 \%$ of the LTC group patients $(2 / 10)$, but the reoperation was not performed in them. Anastomic leakage occurred in 
$20 \%$ of the LTC group patients (2/10) and in $10.3 \%$ of the OTC group patients (3/29), without significant difference between them. The single mortality occurred in a 30-year-old woman with ulcerative colitis who was received the preoperative steroid administration at a total dose of $25,000 \mathrm{mg}$, had a complication of bowel obstruction due to advanced rectal cancer and was already at poor risk preoperatively. She suffered from severe pouchitis complicated with methicillin-resistant Staphylococcus aureus enteritis on the 72 operative day and died.

\section{DISCUSSION}

Laparoscopic procedure in colorectal disease has been reported to cause earlier recovery of the bowel functions, shorter hospital stay, and earlier recovery to working and daily life activities compared with open surgery $[3,5]$. The indications of the operation in ulcerative colitis include rapid aggravation of general conditions, massive blood loss, toxic megacolon, refractoriness to more than $15,000 \mathrm{mg}$ of the steroids. Therefore, the operative procedure for ulcerative colitis is recommended to be less invasive and to cause few complications. The treatment opinions for familial adenomatous polyposis has been widely accepted for total colectomy, because the risk of dying from rectal cancer after colectomy and ileorectal anastomosis is $2 \%$ at 5 year after operation [15] and about the same as that from accidental death and less than that from either desmoid tumors or duodenal cancer [16]. The comparison of laparoscopy assisted total colectomy with conventional procedure so far reported revealed no difference in the time to oral intake and postoperative hospitalization and rather increase of the mean length of operative time and rate of transfusion in the laparoscopic group [9-11]. The role of laparoscopyassisted total colectomy is still unclear. From such viewpoint, minilaparotomy combined laparoscopy and conventional procedure were compared as to less invasiveness.

Minilaparotomy combined laparoscopic procedure is a combination of laparoscopic surgery and minilaparotomy. Two points in our operative technique are notable. First, the lateral peritoneal attachments of the right and left colon are mobilized laparoscopically. Second, a minimally invasive, minilaparotomy using Omni Tract Retracter involves vascular ligation, resection and reanastomosis of the bowel through an incision. The patients who need a full view of the abdomen and require mobilization of distant structures may be best approached by laparoscopy. Minilaparotomy may be best for straight forward and simple resection in patients with the redundant colon. Operative time was not different between the procedures. It depends on the experience of the surgeon, first assistant, camera operator, and nursing staffs, obesity of the patient, cancer complication, and many other factors.

Postoperative nasogastric decompression tube is one of the most uncomfortable factors for patients. In the LTC group, it could be removed as early as POD 1.2 and relieved them from pain. Passage of stool through stoma was also earlier in this group. It is suggested to be because, in the OTC group, intraoperative exposure of the small intestine to outside the abdominal cavity was longer and circulatory damage in the small intestine was severer. Hospital stay was not significantly differentiated between the LTC and OTC groups. In one case of ulcerative colitis in the LTC group, postoperative recovery of the intestinal tract was early and, due to early solidification of watery stool, a temporary stoma could be occluded on the 30th postoperative day during the initial hospitalization. An another two cases of ulcerative colitis and familial adenomatous polyposisin in the LTC group underwent ileal pouchanastomos without temporary ileostoma prospectively and prolonged the hospitalization of the LTC group.

The results of this study demonstrated less invasiveness and earlier postoperative recovery and less postoperative ileus by laparoscopy combined procedure than by conventional procedure [17]. Earlier recovery is postulated to be because of less operation-induced stress, less pain, smaller abdominal incisions and less circulatory damages by shorter exposure of the intestinal tract outside the abdominal cavity. The incidence of wound infections was higher because the wound is strongly suspended in the operation through a small incision wound. However, no infection extended to the deep tissues or required the treatment with antibiotics. As stated in a report that pelvic dissection is very difficult laparoscopically when the field is obscured with blood and efforts are being made maintain ongoing hemostasis [11], we consider that the pelvic dissection should be done under direct vision through a small wound.

In conclusion, this early experience seems to indicate that minilaparotomy combined laparoscopic total colectomy has many advantages and is excellent operative procedure because of smaller incision wound than by conventional open laparotomy, less 
circulatory damages of the intestinal tract in a similar degress to those by laparoscopic surgery as a result of no intraoperative exposure of the small bowel outside the abdominal cavity, earlier postoperative recovery bowel functions and discharge, and less postoperative ileus.

\section{REFERENCES}

1. Romos JM, Beart RW, Goes R, Ortega AE, and Schlinkert RT. Role of laparoscopy in colorectal surgery. Dis Colon Rectum 1995; 38:494-501.

2. Cooperman AM, Kats V, Zimmon D, and Bootero G. Laparoscopic colon resection. J Laparoendosc Surg 1991; 1:221-224.

3. Wexner SD, and Johansen OB. Laparoscopic bowel advantages and limitations. Ann Med 1992; 24:105-110.

4. Vanye TM, Cattey RP, and Henry LG. Laparoscopically assisted colon resections compare favorably with open technique. Surg Laparosc Endosc 1994; 4:25-31.

5. Beart RW. Laparoscopic colectomy: status of the art. Dis Colon Rectum 1994; 37:847-849.

6. Milsom JW, Lavery IC, Church JM, Stolfi VM, and Fazio VW. Use of laparoscopic techniques in colorectal surgery. Dis Colon Rectum 1994; 37:215-218.

7. Musser DJ, Boorse RC, Madera F, and Reed JF. Laparoscopic colectomy: at what cost? Surg Laparosc Endosc 1994; 4:1-5.

8. Aylett SO. Dissection on the surgery of ulcerative colitis. Proc R Soc Med 1953; 46:1032-1035.
9. Wexner SD. The double-stapled ileal reservoir and ileoanal anastomosis: A prospective review of sphincteric function and clinical outcome. Dis Colon Rectum 1991; 34:487-494.

10. Church JM. Familial adenomatous polyposis: a review. Perspect Colon Rectal Surg 1995; 8:203-225.

11. Wexner SD, Johansen OB, Nogueras JJ, and Jagleman DG. Laparoscopic total abdominal colectomy: prospective trial. Dis Colon Rectum 1992; 35:651-655.

12. Peter WR. Laparoscopic total proctocolectomy with creation of an ileostomy for ulcerative colitis. J Laparoendosc Surg 1992; 2:175-178.

13. Schmit SL, Wexner SD, Nogueras JJ, and Jagleman DG. Does laparoscopic-assisted ileal pouch-anal anastomosis reduce the length of hospitalization? Surg Endosc 1993; 7:265-269.

14. Araki $\mathrm{Y}$, Isomoto $\mathrm{H}$, Shirouzu $\mathrm{K}$, Morodomi $\mathrm{T}$, and Kakegawa T. A study on polyethylene glycol electrolyte lavage solution and sodium picosulfate combined pretreatment method for colonoscopy. Kurume Med J 1992; 39:117-121.

15. DeCosse JJ, Bulow S, and Neale K. Rectal cancer risk in patients treated for familial adenomatous polyposis. $\mathrm{Br} \mathrm{J}$ Surg 1992; 79:1372-1375.

16. Arvanitis ML, Jagelman DG, and Fazio VW. Mortality in patients with familial adenomatous polyposis. Dis Colon Rectum 1990; 33:639-642.

17. Seganore A, Luchtefeld M, Mackeigan J, and Mazier $\mathbf{P}$. Open colectomy versus laparoscopic colectomy: are there differences? Ann Surg 1993; 59:549-554. 